\title{
Introduction: Talking STS
}

\author{
FADHILA MAZANDERANI \\ UNIVERSITY OF EDINBURGH \\ PABLO SCHYFTER 2 \\ UNIVERSITY OF EDINBURGH \\ ISABEL FLETCHER \\ UNIVERSITY OF EDINBURGH
}

\begin{abstract}
Talking STS is a collection of interviews and accompanying reflections on the origins, the present and the future of the field referred to as Science and Technology Studies or Science, Technology and Society (STS). The volume assembles the thoughts and recollections of some of the leading figures in the making of this field. The occasion for producing the collection has been the fiftieth anniversary of the founding of the University of Edinburgh's Science Studies Unit (SSU). The Unit's place in the history of STS is consequently a recurring theme of the volume. However, the interviews assembled here have a broader purpose - to present interviewees' situated and idiosyncratic experiences and perspectives on STS, going beyond the contributions made to it by any one individual, department or institution. Both individually and collectively, these conversations provide autobiographically informed insights on STS. Together with the reflections, they prompt further discussion, reflection and questioning about this constantly evolving field.
\end{abstract}

\section{Keywords}

STS; interviews; history; science and technology studies; science studies; Edinburgh

\section{Talking STS}

2016 marked the 50 anniversary of the University of Edinburgh's Science Studies Unit (SSU) (http://www.stis.ed.ac.uk/ssu50), a milestone that was celebrated with a variety of events and talks. Early in the planning process a small group of colleagues based in the present day Science, Technology and Innovation Studies (STIS) subject group at the University of Edinburgh

'Fadhila Mazanderani, Email: f.mazanderani@ed.ac.uk

2 Pablo Schyfter, Email: p.schyfter@ed.ac.uk

${ }_{3}$ Isabel Fletcher, Email: I.Fletcher@ed.ac.uk

Copyright () 2018 (Fadhila Mazanderani, Isabel Fletcher, Pablo Schyfter). Licensed under the Creative Commons Attribution Non-commercial No Derivatives (by-nc-nd). Available at estsjournal.org. 
discussed different ways that we might contribute to commemorating, or more accurately reflecting on, the emergence and stabilization of STS as a distinctive interdisciplinary field. One idea that soon gained traction was to carry out a series of interviews with key figures in the field; we would then compile them into an edited collection of "conversations."

Initially, we thought that this would support a history of the SSU, built using interviews with former members and those who had engaged with the group in substantial ways. As we brainstormed, planned, and discussed the place of the SSU in the development of STS, our ambitions changed. Rather than limiting ourselves to people involved in the early days of Science Studies at Edinburgh, we decided to conduct a more expansive, and hopefully inclusive, series of interviews. Our ambition was not to produce a comprehensive, definitive history of STS, nor to develop one single perspective on what the field has been, is now and ought to be in the future. Instead, we sought diverse perspectives. We hope that by having done so, this project will stimulate and nourish discussion and debate. Ideally, readers will encounter ideas with which they concur, others with which they disagree, and many more that demand prolonged musing. Importantly, Talking STS is not a celebratory exercise. We care as much about the field's flaws, failures, and inconsistences as we do about its abilities and triumphs.

Talking STS consists of conversations between key STS scholars (interviewees) and earlyto mid-career colleagues (interviewers), many but not all of whom are currently based at or have an association with the University of Edinburgh. A short reflection piece, written by each interviewer, accompanies the corresponding exchange. Our team of interviewers together chose whom we would approach for these conversations. Unsurprisingly, people had distinct, often strongly held, opinions about the scholars we should include and which of them they personally would like to interview. After much discussion, we arrived at, if not a consensus, at least a compromise on whom to invite. Invariably, a range of factors, from geography and logistics to personal preference and availability, played a role in who ended up taking part in the interviews. Most of the people we invited kindly agreed to take part. In hindsight, we were quite naïve when we started the project, since we did not anticipate fully the agonies that any attempt of selecting "key figures" would induce. There are many more voices that we would have liked to include here, and we apologize for the absences. In the end, time and other constraints made us stop at the conversations presented here.

Overall, Talking STS embraces and exploits diversity and peculiarity. Each conversation is distinct in its structure and substance, not simply because the talkers differ, but because we encouraged uniqueness. We compiled and distributed a set of questions to help prompt discussion, but allowed our colleagues a great deal of freedom to structure their respective conversations in whichever manner they felt was best. Consequently, the conversations together offer readers a mix of styles and content. The accompanying reflections display even greater variability. We did not institute formats, dictate tasks to fulfill, or require specific material.

The conversations contain a range of different, yet complementary "origin" stories about the field of STS. Each interviewee, in true STS fashion, stresses that their own version of events is situated and partial, shaped by personal biographies, intellectual commitments, and institutional contexts. From these accounts, STS emerged inter alia out of: an anti-Mertonian sociology of 
science characterized by a desire to look inside science, at how it actually works in practice; the radical science movement and political activism propelled by a concern with the social and environmental consequences of science, especially those associated with nuclear technologies; particular intellectual and methodological traditions that turned their attention to science, such as feminism, ethnomethodology, discourse analysis, labor studies and public policy. Why and how these different concerns evolved into what we now refer to as STS (indicating either "science and technology studies" or "science, technology, and society," depending on who is speaking) differed across countries and institutions, and each of the conversations presented here provides a specific lens into this history.

Almost all of our interviewees explicitly foregrounded the often overlooked, mundane, everyday work that plays a crucial role in the development of any field: the creation, coordination, and institutionalization of early research groups, departments, and teaching programs; the establishment of scholarly bodies and events, such as the Society for Social Studies of Science (4S) and the European Association for the Study of Science and Technology (EASST); and the development and on-going editorship of key journals, such as Social Studies of Science (SSS). While each interviewee names individuals who were particularly instrumental in relation to their own careers and the specific contexts within which they work(ed), David Edge-the first Director of the SSU and long-term editor of SSS-consistently appears across the corpus of conversations. Even though Edge's contribution to STS has been widely acknowledged, including through the receipt of the John Desmond Bernal Prize in 1993, his name is less well known amongst the younger generation of scholars (including many of the Talking STS interviewers). We mention Edge because his presence in the interviews, and similar references to other early-day figures, serve as salient reminders of the indispensability of the invisible work that goes into creating and maintaining any scholarly endeavor.

Though we did not specify topics to explore, common themes emerge across the interviews. First is the perplexing, oft-repeated question of what constitutes STS, especially as our objects of study have increasingly moved away from science narrowly understood to include areas like medicine, business, finance, the humanities, and the arts. Is it a discipline, a nondiscipline, a multidiscipline, a field, an orientation, a set of commitments and sensibilities, or some or all of the above? Our interviewees invariably had different perspectives on this. However, a common thread that binds them is a strong sense of unity, not only in spite of, but also as a result of, this apparent disunity. Thus, the plurality and fragmentation of STS, while at times seen as a challenge and a shortcoming, also paradoxically emerges as one of its core strengths. It is able to transform, travel, and re-invent itself yet retain a distinctive orientation, somewhat like a musical instrument has a specific register within the orchestral collective and across different pieces played.

Which notes sit in the STS register, according to the conversations collected here? A commitment to empirical research, to studying practices in-depth, in order to generate rather than impose theory. A questioning of the status quo (remember: it could be otherwise!), allied with a willingness to open black boxes. An openness to alternative ways of thinking and doing, both amongst colleagues within the field and in relation to our objects of study. A set of 
interrelated, though not necessarily inter-changeable values, such as epistemic humility and responsibility. A critical awareness of the reflexive nature of all knowledge production, including our own, and often a sense of humor, irony, adventure, and irreverence. Yet, as our interviewees repeatedly state, STS is also characterized by its failures, mis-directions, and contradictions. Some claim that the field has grown complacent regarding topics and issues that were once central, like in-depth empirical studies of science. Others criticize a tendency to foreground "fashionable" and fundable research areas and agendas. And others still lament a failure to engage more actively in the types of politics that once motivated and justified the field.

Just as the conversations collected here showcase different perspectives on the history of STS, so too do they open up different visions and expectations about its future. In some accounts, the future of STS relies on the continued consolidation of the field through the establishment of appropriate undergraduate and postgraduate training, alongside the development of a clear intellectual canon. In others, an emphasis is placed on expansion through diffusion and influence in other fields and areas, as well as in public life. Regardless of the position they adopt, none of our interviewees is complacent or self-congratulatory. Indeed, some advocate a radical rethinking of the field, even a veritable "blowing-up of STS."

We hope that you enjoy Talking STS, as individual conversations and a collection, and that your interpretations are as diverse as the conversations and reflection pieces collated here. If a reader can find resonance with ideas that she finds here and gain support for her views, then our project has succeeded. But so too will it succeed if a reader disagrees with material, becomes frustrated, and is induced to criticize. If what our participants express seems not to reflect what our field is or what it ought to do, then readers may feel encouraged to posit different ways, perhaps (hopefully?) contrarian, to understand what STS should aim to accomplish. Put more simply, here we offer episodes of people talking and reflections on those exchanges. Do what you will with what they say.

Lastly, we would like to thank everyone who has been involved in this project. This includes the interviewees and interviewers who gave generously of their time and experience, but also colleagues at STIS who supported the project in other ways, most especially: Steve Sturdy, Catherine Lyall, and Robin Williams. Thokozani Kamwendo did a brilliant job of editing the interviews and collating information for this project-thank you! We gratefully acknowledge the financial support we received from the University of Edinburgh's School of Social and Political Science, which made this project possible. 